\title{
Trabalhadores do lazer do Programa Esporte e Lazer da Cidade: uma aproximação à definição do perfil
}

\author{
Dulce Filgueira de Almeida* \\ Ingrid Dittrich Wiggers ${ }^{* *}$ \\ Ana Amélia Neri***
}

\begin{abstract}
Resumo: O artigo tem como objetivo caracterizar o perfil de trabalhadores do lazer do Programa Esporte e Lazer da Cidade. Fundamentou a análise a definição dos trabalhadores do lazer como status ocupacional. Foram coletados dados, por meio de um questionário, nas esferas nacional, bem como no Distrito Federal. Os resultados apontam coincidência do perfil entre as esferas pesquisadas. A discussão dos dados indicou que há uma associação entre o tempo de permanência no programa, a participação dos agentes nos encontros formativos e o conhecimento das noções fundamentais do programa. A formação continuada representa uma estratégia fundamental para consecução da política examinada.
\end{abstract}

Palavras-chave: Trabalhadores do Lazer, Política Pública, Lazer.

\section{INTRODUÇÃO}

O presente artigo é um recorte de uma pesquisa realizada nacionalmente e que teve como objetivo geral analisar o "Programa Esporte e Lazer da Cidade" (PELC), do Ministério do Esporte do Brasil. Como um dos objetivos específicos destaca-se a construção do perfil de trabalhadores do lazer - que são os agentes sociais do

\footnotetext{
"Professora, Programa de Pós-Graduação em Educação Física, Universidade de Brasília, Brasília, DF, Brasil. E-mail: dulce.filgueira@gmail.com

"Professora Programa de Pós-Graduação em Educação Física, Universidade de Brasília, Brasília, DF, Brasil. E-mail: ingridwiggers@gmail.com

"*Pesquisadora do Núcleo da Rede CEDES da UnB, Brasília, DF, Brasil. E-mail: anaaneri@gmail.com
} 
programa -, considerando aspectos socioeconômicos, tempo de permanência no programa, processo de formação continuada e conhecimento sobre os objetivos, princípios e diretrizes ${ }^{1}$. Resulta, portanto, de parte de uma pesquisa, que teve como delineamento metodológico o estudo de caso e que foi composta por várias etapas de investigação além da apresentada no texto que se segue.

O Programa Esporte Lazer da Cidade visa a assegurar o esporte e o lazer como direito social e, desse modo, contribuir para exercício pleno da cidadania (TELLES, 1999). Sob essa perspectiva, o esporte e o lazer são abordados como bens culturais, cujo acesso atende ao princípio da universalização e da inclusão social, que são, por sua vez, norteadores da "Política Nacional de Esporte e Lazer" (BRASIL, 2006). Para esse fim, o programa é desenvolvido por um conjunto de agentes sociais que atuam em "Núcleos de Esporte e Lazer", que se localizam em cidades do território nacional. Ressalve-se que tais agentes são ao mesmo tempo executores do programa e membros das respectivas comunidades onde atuam por meio da oferta de atividades de esporte e lazer, como ginástica, capoeira, jogos, dança e esportes propriamente ditos (FIGUEIREDO; ALMEIDA, 2010, ALMEIDA et al., 2012).

Assim, definir a caracterização do perfil dos trabalhadores do lazer pressupõe entender quem são esses atores sociais. No âmbito deste trabalho, optamos por considerá-los como um status ocupacional organizado ou quase-organizado (SOROKIN, 1979) para desenvolver atividades de esporte e lazer comunitariamente. Conhecer o seu perfil tem implicações na qualificação de estratégias para sua formação continuada e, por conseguinte, possibilita elementos para o melhor delineamento do programa social, no que concerne ao tipo de ação/intervenção realizada em comunidades. Assim como na área do lazer, em outras, tal qual a da saúde, os agentes comunitários se revelam atores sociais importantes para as políticas públicas. Os agentes comunitários representam o elo entre a comunidade e o

\footnotetext{
${ }^{1}$ A pesquisa foi financiada pela Financiadora de Estudos e Projetos - FINEP. Durante a realização desta etapa da pesquisa, a primeira autora contou com a concessão de bolsa de pós-doutoramento da Coordenação de Pessoal de Aperfeiçoamento de Nível Superior - CAPES.
} 
Estado, mediando as necessidades da comunidade com as demandas das ações políticas. "Esse destaque evidencia a necessidade de se desenvolverem estudos sobre o seu perfil ocupacional, social e processo de formação" (CORIOLANO et al., 2012, p. 54).

Para a caracterização desses atores sociais sob a perspectiva de definição dos trabalhadores do lazer como status ocupacional, acrescente-se que a pesquisa não se baseia apenas em dados da esfera nacional, mas também da local, neste caso, do Distrito Federal e seu entorno. A escolha do lócus se justifica pela pretensão em compreender com maior profundidade a realidade brasileira e do Distrito Federal e entorno, esta última comumente expressa como singular para o caso brasileiro, tendo em conta indicadores socioeconômicos, como os apresentados pelo Índice de Desenvolvimento Humano - IDH. É preciso considerar que, ao se tomar macroestruturas como unidade básica de análise, "[...] ficam invisíveis desigualdades e problemas existentes [...]" dentro dela (POCHMANN; AMORIM, 2003, p. 19). Isto porque, ao trabalharse com dados numéricos, pode-se revelar uma face do problema, enquanto outras permanecem ocultas.

Utilizou-se, por conseguinte, de uma análise comparativa ancorada em dados descritivos, cujas variáveis são, em sua maior parte, independentes, mas que ajudam, aos seus modos, a revelar o perfil do grupo que se constitui, pelo status ocupacional, trabalhadores do lazer. Estes dados foram coletados conforme a aplicação de um questionário, cujas informações serão utilizadas para o desenvolvimento da análise à que se propõe esse artigo.

\section{PrincíPIOS E diRetrizes do PROGRAMA ESPORTE E LAZER DA CIDADE}

O Programa Esporte e Lazer da Cidade foi criado em 2003, com o objetivo precípuo de "promover o acesso ao esporte recreativo e ao lazer", em consonância ao Plano Plurianual (2004-2007), intitulado "Brasil: um país de todos" (BRASIL, 2008). Assenta-se na 
compreensão de que há desigualdade de acesso ao esporte e lazer para parte significativa da população brasileira, o que impõe a necessidade de políticas e programas que visem à correção dessa diferença de acesso (FIGUEIREDO, 2009, FERES NETO; VIEIRA; ATHAYDE, 2012). O programa recebeu um montante de R\$ 730 milhões por parte do governo federal, entre 2004 e 2008. Representou, no período, o maior investimento para esporte e lazer com fins educacionais e de participação, o que o coloca em posição de destaque no atual cenário das políticas públicas (ALMEIDA; MARCHI JÚNIOR, 2010).

Como um programa social, o PELC apresenta em seu escopo os princípios norteadores da Política Nacional do Esporte (PNE), expressos da seguinte forma: a) Da reversão do quadro atual de injustiças sociais, exclusão e vulnerabilidade social; b) Do esporte e do lazer como direito de cada um e dever do Estado; c) Da universalização e inclusão social; c) Da democratização da gestão e da participação (BRASIL, 2008).

Com base nesses princípios norteadores, foram definidas diretrizes para o programa, que se constituem por: a) autoorganização comunitária; b) trabalho coletivo; c) intergeracionalidade; d) fomento e difusão da cultura local; e) respeito à diversidade (BRASIL, 2008). Neste particular, as duas primeiras diretrizes - a da "auto-organização comunitária" e a do "trabalho coletivo" - aliadas aos princípios norteadores que consideram o esporte e o lazer como direitos e à democratização da gestão e da participação, apresentamse como fundamentais para o entendimento da análise que ora se pretende desenvolver. Isto porque a relação destas diretrizes com estes princípios permite a compreensão da ênfase dada pelo programa na qualificação dos atores sociais que dele participam, em especial dos agentes sociais, aqui entendidos como trabalhadores do lazer.

\section{DEFINIÇÃO DO PERFIL DE ATORES SOCIAIS}

A definição de perfis parte de uma premissa: "para que cada um deles possua uma natureza que lhe é própria, é necessário que 
possua também condições de existência que lhe são específicas" (DURKHEIM, 1987, p. 129)². Isto quer dizer que, com base na caracterização tipológica dos trabalhadores do lazer, é possível vislumbrar arranjos de causalidade entre as relações todo-parte e parte-todo, entre a sociedade e o indivíduo, portanto. Nesse processo, tal definição possibilitará uma aproximação à compreensão de quem são os agentes sociais que atuam junto ao Programa Esporte e Lazer da Cidade. Assim, para melhor entender este universo, foi necessária a realização de mediações teórico-metodológicas, fundamentadas na perspectiva de Sorokin (1979) e Weber (1991).

Podemos supor que a constituição de grupos em perfis pode trazer elementos para a compreensão de quem são os trabalhadores do lazer que atuam no programa ora investigado. Por outro lado, é possível, conforme a compreensão de Sorokin (1979), para quem os vínculos econômicos e ocupacionais, mesmo utilizados separadamente, exercem forte influência sobre o corpo e a mente dos sujeitos, entender o comportamento e o modo de vida desses atores. Explica ainda o autor que:

\begin{abstract}
Pessoas que têm ocupações, posição econômica acrescentaríamos níveis de escolaridade - e direitos e deveres essencialmente análogos se tornam semelhantes de várias outras maneiras, tanto no comportamento quanto física, mental e moralmente, ainda que isto não signifique a igualdade, mas possibilidade de inserção destes sujeitos em grupos sociais (SOROKIN, 1979, p. 87).
\end{abstract}

As características descritivas aqui expressas, tais como sexo, estrato etário, escolaridade, dentre outras, constituem apenas uma parte do todo, isto é, constituem-se em elementos capazes de rastrear o perfil dos atores sociais que executam o programa em suas comunidades, sobretudo quando combinadas ao tempo de

\footnotetext{
'É necessário esclarecer que o uso da contribuição durkheimiana para a definição da caracterização tipológica nada tem a ver com a aproximação teórica da orientação seguida ao longo da pesquisa. O uso que se faz aqui da compreensão de Durkheim está estritamente relacionado à possibilidade de construção de perfis - toma-se como exemplo a análise construída pelo autor no caso da definição de casos de suicídio, com base em sua perspectiva metódica (DURKHEIM, 1987).
} 
permanência no programa - período de atuação -, ao processo de formação continuada e ao conhecimento sobre os objetivos, princípios e diretrizes do mesmo.

Em consonância, pesquisas sobre a formação continuada de agentes comunitários da área de saúde têm evidenciado a correlação positiva entre práticas de formação permanente e a ação dos agentes em suas comunidades. A formação continuada representa, além de aprimoramento profissional, uma estratégia significativa para produzir "um novo olhar" do agente sobre sua prática social, de modo a orientála levando em conta as situações particulares encontradas em cada realidade e buscando agir em parceria com a comunidade. Sobretudo, oferece instrumentos conceituais e tecnologias que capacitam o agente comunitário para a transformação das suas práticas profissionais e da própria organização do trabalho, aproximando-se, por um lado, das necessidades da comunidade e de outro, das noções fundamentais das políticas públicas. De acordo com a concepção de educação permanente mais difundida entre os agentes comunitários de saúde, a atividade do trabalhador pode ser o ponto de partida do processo formativo, gerando, assim, sua aprendizagem subsequente (CORIOLANO et al., 2012, STROSCHEIN; ZOCCHE, 2012, MODESTO et al., 2013).

A definição do status ocupacional, econômico e legal, para utilizar os termos cunhados por Sorokin (1979), combinados aos status em relação à escolaridade e ao sexo dos sujeitos, ajudam a compor o quadro para a definição do perfil dos trabalhadores do lazer. São eles, reiteramos, como atores sociais, sujeitos que constroem ações de intervenção por meio do esporte e lazer em suas comunidades. No entanto, deve-se acrescentar que suas práticas sociais orientamse pelo comportamento de outros sujeitos, seja este comportamento passado, presente ou esperado como futuro. Estas ações são, por seu turno, produtoras de sentido, configurando o conceito de ação social em Weber (1991). 


\section{Delineamento metodológico}

Conforme anteriormente assinalado, nosso objetivo foi identificar a caracterização do perfil de trabalhadores do lazer do Programa Esporte e Lazer da Cidade, considerando aspectos socioeconômicos e forma de ação/intervenção em comunidades. Ressalvamos que, no âmbito do programa, tais trabalhadores são denominados de "agentes sociais". Esses agentes são os executores do programa e integram as respectivas comunidades onde atuam em "Núcleos de Esporte e Lazer". Para além das atividades de esporte e lazer que desenvolvem, eles se reúnem oportunamente em seus núcleos, em encontros pedagógicos e em reuniões nacionais, para participarem de uma ação educativa denominada de "formação continuada", que, de acordo com o manual de orientação do programa, consiste em um dos seus objetivos (BRASIL, 2008).

A literatura recomenda que a metodologia de análise de políticas públicas deve considerar o contexto social onde estão inseridos os programas. Para se compreender a complexidade do processo de formulação e implementação dessas políticas é importante focar outros elementos que ultrapassem aqueles circunscritos ao conceito de políticas como uma estratégia do Estado. Entre esses, é sugerido o entendimento da relação social dos agentes, que se configura como um aspecto preponderante a ser analisado por especialistas da área (STAREPRAVO; SOUZA; MARCHI JUNIOR, 2011).

O universo pesquisado foi composto por $(\mathrm{N}) 3.256$ sujeitos, que corresponde à população total de agentes sociais do programa na esfera nacional (cf. dados de 2007 a 2010). Trabalhando com um erro amostral de 5\%, o tamanho da amostra foi definido por um cálculo básico correspondente a: amostra (a) é igual a $1 / \mathrm{E}^{2}$ (erro estimado ao quadrado). Obteve-se como tamanho da amostra 400 sujeitos e uma confiança de $95 \%$. A pesquisa foi realizada compreendendo duas esferas: a nacional e a local, neste caso, do Distrito Federal e seu entorno. Para assegurar uniformidade dos 
procedimentos, mantivemos esta amostra, igualmente, para as duas esferas pesquisadas. Portanto, os resultados aqui expressos trazem informações de 800 sujeitos participantes, sendo 400 da esfera nacional e 400 da local.

A pesquisa teve como delineamento o estudo de caso, a fim de construir um diagnóstico inicial sobre o perfil dos sujeitos investigados. Para este diagnóstico, utilizamos um questionário composto por vinte e quatro questões, dos tipos "fechadas com múltipla escolha", "escalares", "mistas" e uma questão aberta. Nesta pedia-se para avaliar o programa e, em seguida, tecer comentários a respeito da avaliação. Todos os quesitos possuíam o mesmo peso, exceto a questão final, por ser do tipo aberta. Em outras palavras, não havia atribuição de notas distintivas entre as questões formuladas no questionário, que foi objeto de teste no ano de 2006.

A aplicação do mesmo se deu em dois momentos diferentes. No primeiro, na esfera nacional, durante a Reunião Nacional dos Agentes Sociais do Programa Esporte e Lazer da Cidade ${ }^{3,4}$, em que tivemos respondentes de 15 estados brasileiros: Acre, Amazonas, Bahia, Espírito Santo, Goiás, Maranhão, Mato Grosso, Minas Gerais, Pará, Rio de Janeiro, Rio Grande do Norte, Rio Grande do Sul, Santa Catarina e São Paulo além do Distrito Federal, compreendendo um total de 45 cidades . O segundo momento coincidiu com a intenção de fazer um estudo mais pormenorizado da realidade do Distrito Federal e entorno. No Distrito Federal foram objeto de análise os núcleos instalados em Ceilândia, Taguatinga, Samambaia, Cruzeiro e Núcleo Bandeirante. Participaram ainda as cidades de Valparaíso

\footnotetext{
${ }^{3} \mathrm{~A}$ política de formação do programa que consiste em reuniões nacionais e encontros pedagógicos está relacionada à ação educativa, que conforme documentos oficiais dispostos no sítio do programa diz respeito a: "formação continuada de gestores, agentes, lideranças comunitárias, pesquisadores, legisladores e outros parceiros atuantes nas esferas públicas federal, estadual e municipal, com vistas à formulação e implementação de políticas públicas de esporte e lazer de inclusão social e cultural" (BRASIL, 2011).

${ }^{4}$ Os questionários relativos aos dados expressos na esfera nacional foram obtidos durante a I Reunião Nacional dos Agentes Sociais do Programa Esporte e Lazer da Cidade, que correu em Brasília, no ano de 2006. Esta reunião teve por objetivo principal promover a formação continuada aos trabalhadores do lazer, estando associada à estratégia de ação educativa do referido programa no âmbito do Ministério do Esporte.
} 
e Cidade Ocidental, localizadas no estado de Goiás, mas consideradas parte do entorno do Distrito Federal. Em ambas as esferas pesquisadas a aplicação do questionário ocorreu durante o processo de formação dos agentes sociais.

Informações obtidas na esfera nacional e no Distrito Federal e entorno são aqui analisadas de forma comparativa, por meio da descrição. Para a análise utilizou-se do programa estatístico Statistical Package for the Social Sciences - SPSS versão 15.0.

\section{RESULTADOS: PONTUANDO CARACTERÍSTICAS}

Interpretar dados que remetem à constituição de perfis é parte da atividade de pesquisa que se constitui como descritiva. Dificilmente poderíamos entender o processo de intervenção de um programa uma política em ação - sem que se tenha clareza do perfil dos seus atores sociais, pois, segundo Weber (1991), a ação política pressupõe o exercício da dominação legítima por parte desses. Com efeito, diante do desafio de analisar um programa em realização, um aspecto fundamental a ser considerado é a identificação de quem são os atores sociais.

Com base nos resultados obtidos por meio dos questionários foram cruzadas variáveis no processo de análise, visando tanto sua representação gráfica quanto sua adequada interpretação. De acordo com Bourdieu (1983, p. 86), "os grupos se investem inteiramente, com tudo o que os opõem aos outros grupos, nas palavras comuns onde se exprime sua identidade, quer dizer sua diferença". Sendo assim, as características comuns expressam uma elocução socialmente marcada, carregada de conotações sociais, que podem contribuir para a caracterização do perfil dos atores sociais.

Sexo, idade e instrução, por exemplo, são variáveis independentes. Todavia, ainda que estatisticamente estas variáveis apresentem respostas por si mesmas, não é possível interpretá-las isoladamente. Nesta direção é que combinamos o conjunto de variáveis ou indicadores, para que possamos delinear mais claramente 
o desenho que se espera, ou seja, a definição do perfil de trabalhadores do lazer do Programa Esporte e Lazer da Cidade.

a) Sexo e estratos etários dos trabalhadores do lazer

Quanto à distribuição por sexo dos trabalhadores do lazer verificou-se que, na esfera nacional $54 \%$ são homens e $46 \%$ são mulheres. No Distrito Federal e entorno, os homens representam $60 \%$ e as mulheres $40 \%$. Evidenciou-se, portanto, uma proporcionalidade entre os dados obtidos nas duas esferas pesquisadas.

A faixa etária dos trabalhadores do lazer na esfera nacional varia de 14 a 60 anos de idade, com forte concentração na faixa etária entre 25 e 40 anos. Já na esfera local a idade varia de 14 a 59 e a concentração se dá entre 20 e 40 anos.

b) Escolaridade dos trabalhadores do lazer

Um dos fatores mais importantes para o estabelecimento de indicadores sociais é o nível de escolaridade. Por meio dele é possível compreender, de forma estratégica o que, em termos de políticas sociais, é preciso ser feito para assegurar à população o direito à educação (GUTIÉRREZ, 1988). No caso dos trabalhadores do lazer, identificar seu nível de escolaridade é necessário para o planejamento de ações educativas, voltadas especificamente à formação continuada desses sujeitos sociais.

Para analisar o nível de escolaridade dos informantes, distribuímos o universo amostral em seis estratos: ensino fundamental incompleto e completo, ensino médio incompleto e completo, ensino superior incompleto e completo. Obtivemos que, na esfera nacional, $48 \%$ dos informantes possuem nível superior completo, 24\% nível superior incompleto, $18 \%$ nível médio completo, $4 \%$ nível médio incompleto e $6 \%$ nível fundamental completo. Não há registro de nível fundamental incompleto. Na esfera local, tivemos que $8 \%$ possuem nível superior completo, $10 \%$ nível superior incompleto, 
40\% nível médio completo, 20\% nível médio incompleto, 10\% nível fundamental completo e $12 \%$ nível fundamental incompleto.

c) Tempo de permanência dos trabalhadores do lazer no Programa Esporte e Lazer da Cidade

Outro aspecto relevante para a compreensão da caracterização do perfil dos trabalhadores do lazer diz respeito ao tempo de permanência, isto é, de atuação no programa. Determina tal relevância a constatação de que a continuidade da intervenção e do conhecimento das suas estratégias são fatores atrelados ao tempo em que o trabalhador exerce suas atividades no programa, conforme se observa nos Gráficos 1 e 2 .

Gráfico 1 - Tempo de permanência no programa (nacional)

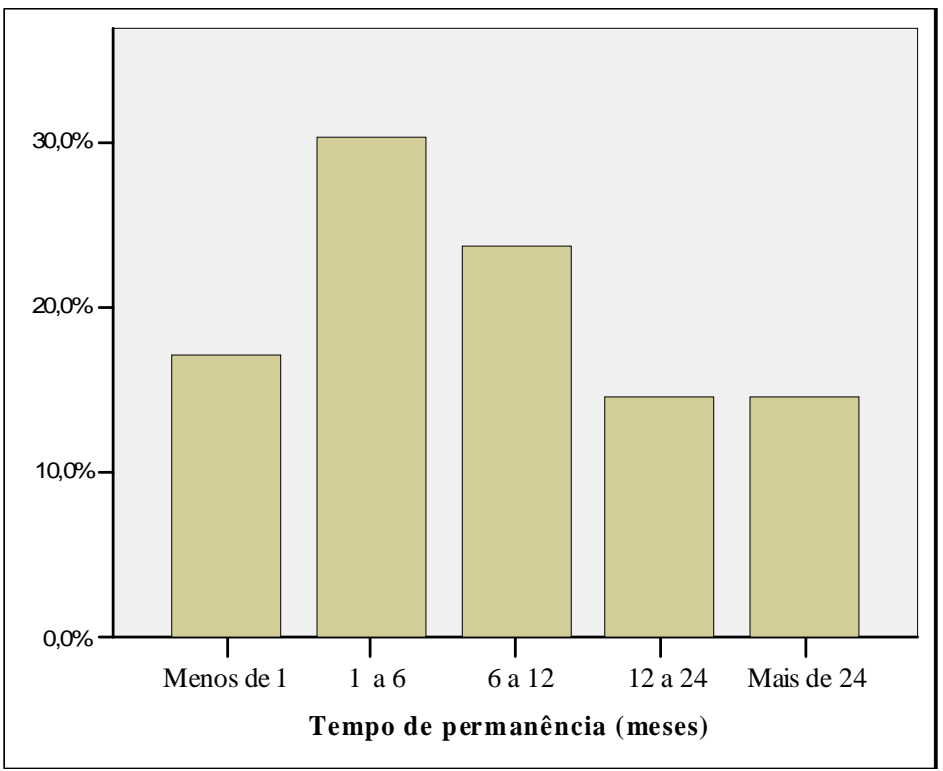

Fonte: Autoras (2010). 
Gráfico 2 - Tempo de permanência no programa (local)

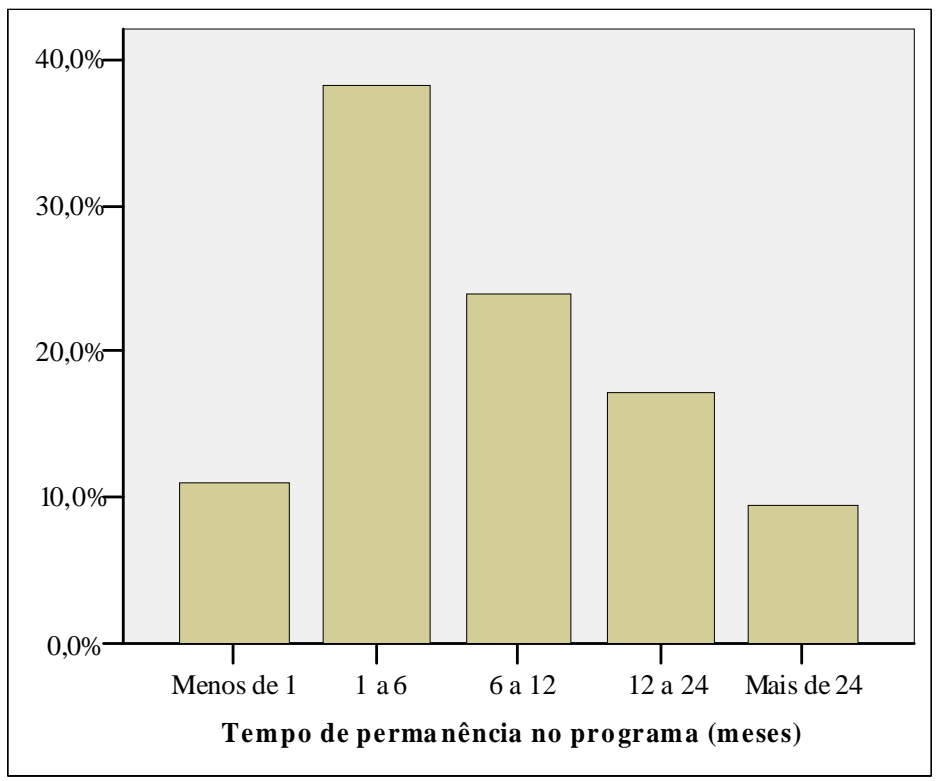

Fonte: Autoras (2010).

Comparando-se os Gráficos 1 e 2, verifica-se que o maior grupo de trabalhadores encontra-se na faixa compreendida entre um e seis meses de atuação no programa. Esse aspecto confirma a existência de considerável transitoriedade, posto que apenas aproximadamente $15 \%$ dos inquiridos na esfera nacional têm mais de dois anos no programa, enquanto na esfera local este percentual cai para cerca de $10 \%$.

De acordo com os dados apresentados, aproximadamente $75 \%$ dos entrevistados encontram-se participando do programa há menos de um ano. Esta informação é interessante, pois o reconhecimento das lideranças comunitárias pode estar relacionado ao carisma e à capacidade de intervenção das mesmas em suas comunidades, inclusive no que diz respeito à constituição de novos quadros. Porém, a formação de quadros não se dá de modo contínuo, posto que há transitoriedade em relação ao tempo em que o trabalhador do lazer permanece no programa. 
A esse respeito alguns questionamentos são importantes: a que se deve essa transitoriedade, visto que o programa, na época da pesquisa, estava implantado há mais de três anos e, no entanto, um percentual relativamente baixo de trabalhadores está em atividade desde o seu início? Como consolidar um programa social - no quadro das políticas sociais brasileiras - com uma situação de transitoriedade como esta?

d) Processo de formação continuada dos trabalhadores do lazer

Também se procurou obter informações sobre a formação continuada durante o processo de intervenção dos agentes sociais. $\mathrm{O}$ processo de formação compreende dois tipos. O primeiro, com base na realização de reuniões nacionais, é de responsabilidade do Ministério do Esporte. O segundo, que ocorre nos locais em que são implantados os núcleos do programa, onde, portanto, vivem os trabalhadores do lazer, é de responsabilidade das instituições conveniadas, que recebem os recursos e realizam a formação, devendo, posteriormente, prestar contas ao Ministério do Esporte. Para saber se havia ou não a participação no processo de formação, a questão foi apresentada de forma bipolar, isto é, o entrevistado só poderia responder "sim" ou "não", não havendo outra alternativa. Verificou-se que mais de $85 \%$ dos entrevistados na esfera nacional já participaram de algum processo de formação ou capacitação e quase $80 \%$ disseram ter participado desse processo no Distrito Federal e entorno. Há clara aproximação entre os resultados obtidos, pois há preponderância nas duas esferas (nacional e local) de respostas afirmativas.

e) Conhecimento dos trabalhadores em relação aos objetivos, princípios e diretrizes do Programa Esporte e Lazer da Cidade

O nível de conhecimento dos trabalhadores do lazer sobre os objetivos, princípios e diretrizes do programa também foi objeto de interesse desta pesquisa. Por meio dessa questão, tinha-se como propósito compreender até que ponto os sujeitos apresentavam domínio e compreensão do programa em que trabalhavam, bem como se tinham clareza a respeito da forma de sua atuação. A pergunta feita com essa finalidade foi: "você conhece os objetivos, princípios 
e diretrizes do Programa Esporte e Lazer da Cidade?" Para a melhor análise dos dados obtidos, cruzamos os mesmos com os números registrados a respeito do tempo de permanência no programa.

Em função da complexidade da distribuição dos informantes por tempo de permanência no programa e visando construir uma análise pormenorizada desta categoria, realizamos a descrição analítica conforme a seguinte distribuição em grupos: grupo 1 - menos de um mês no programa; grupo 2 - mais de um mês e menos de seis meses; grupo 3 - mais de seis meses e menos de um ano; grupo 4 mais de um e menos de dois anos; e grupo 5 - mais de dois anos. Geraram-se os Gráficos 3 e 4, que se apresentam interessantes para compreender o universo pesquisado, de acordo com análise apresentada posteriormente.

Gráfico 3 - Conhecimento dos objetivos, princípios e diretrizes X Tempo de permanência (nacional)

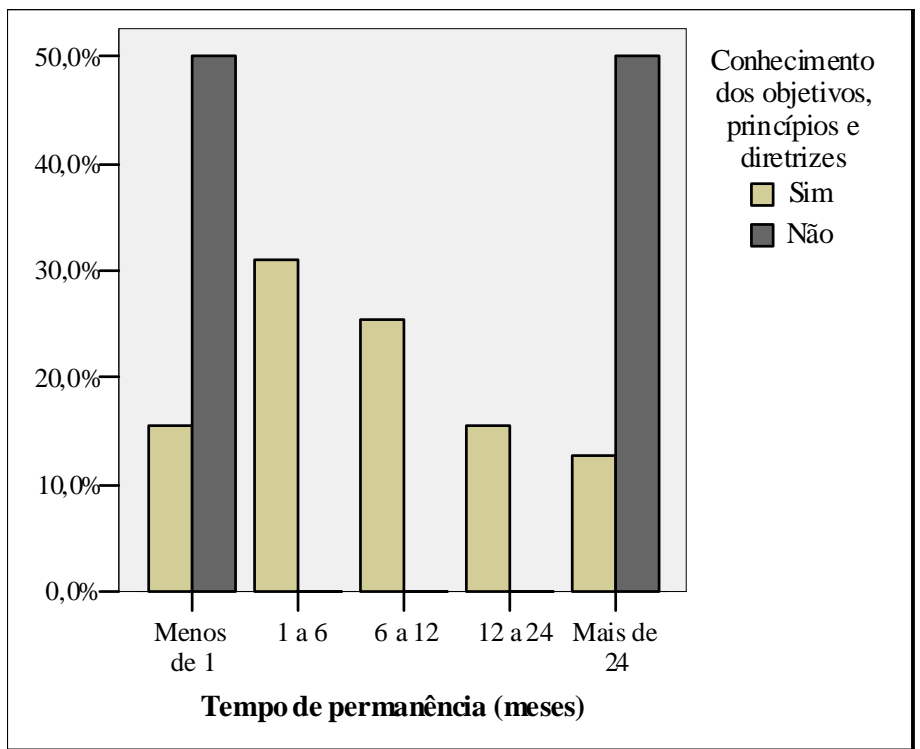

Fonte: Autoras (2010).

Movimento, Porto Alegre, v. 20, n. 01, p. 215-238, jan/mar de 2014. 
Gráfico 4 - Conhecimento dos objetivos, princípios e diretrizes X Tempo de permanência (local)

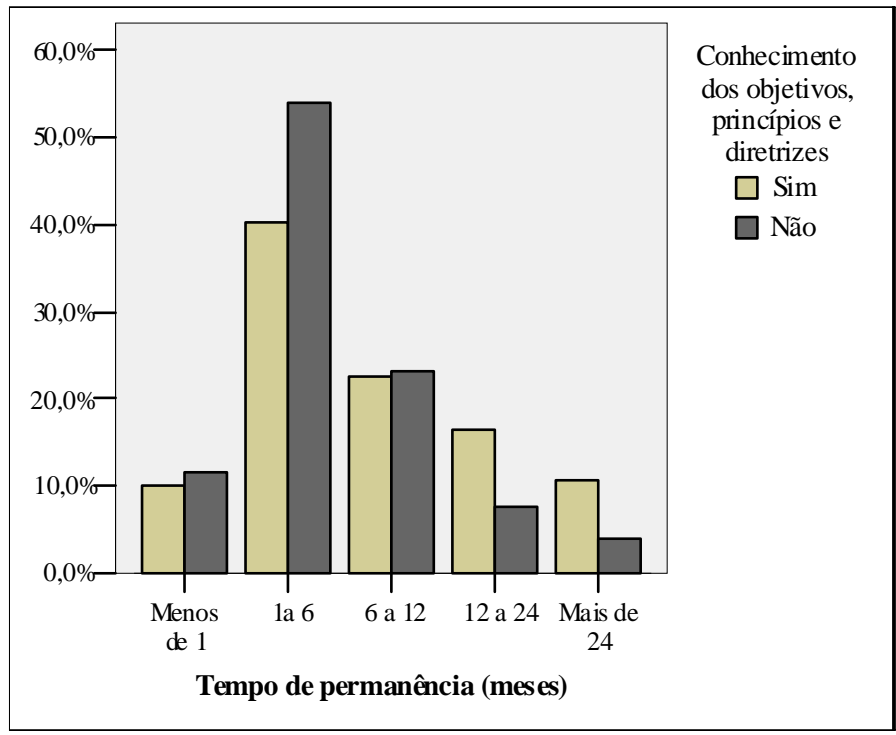

Fonte: Autoras (2010).

Por fim, como se pode perceber do que demonstram os Gráficos 5 e 6 , na esfera nacional, obtivemos como resposta que $16 \%$ dos trabalhadores do lazer não participaram dos encontros pedagógicos dedicados ao planejamento, execução e avaliação das atividades desenvolvidas nos núcleos. Na esfera local, aproximadamente $6 \%$ dos entrevistados indicaram não participar dos referidos encontros. $\mathrm{O}$ fato de ser a participação em tais eventos obrigatória aponta para a necessidade de um acompanhamento mais efetivo por parte dos gestores dessa etapa programa. 
Gráfico 5 - Participação nos encontros pedagógicos (nacional)

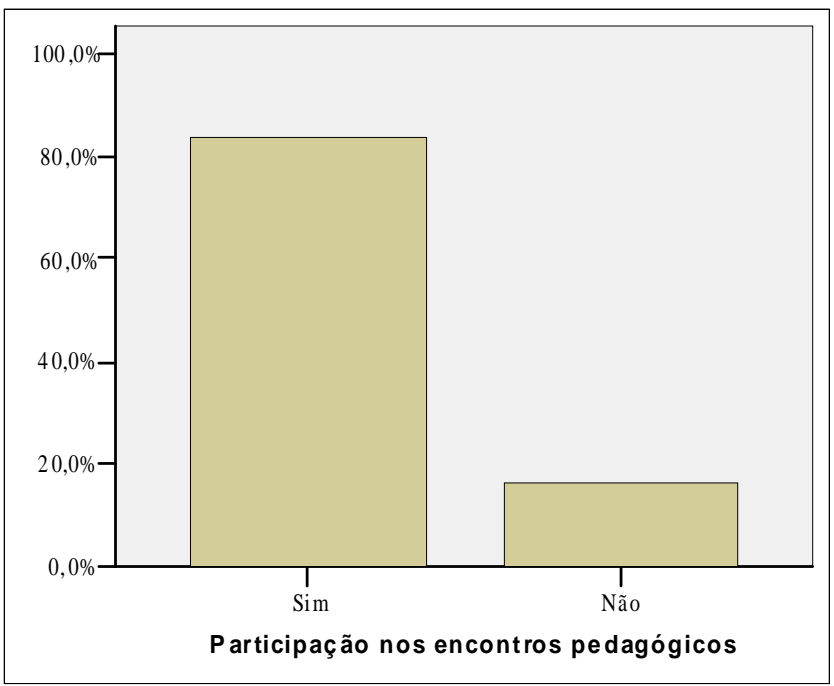

Fonte: Autoras (2010).

Gráfico 6 - Participação nos encontros pedagógicos (local)

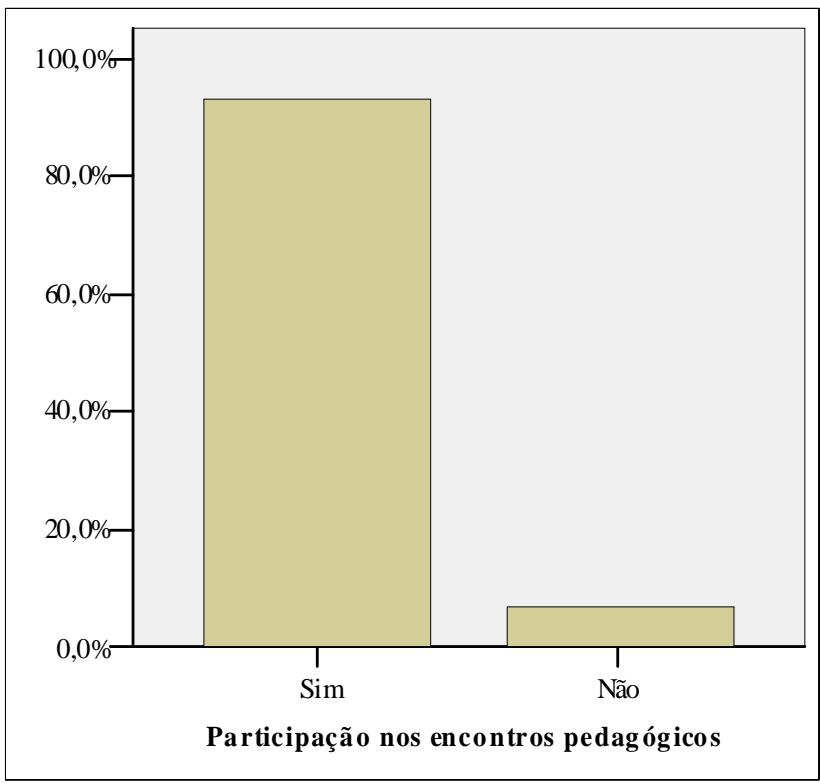

Fonte: Autoras (2010).

Movimento, Porto Alegre, v. 20, n. 01, p. 215-238, jan/mar de 2014. 


\section{Discussãoe ANÁLISE dOS RESULTADOS}

A discussão que ora apresentamos diz respeito, primeiramente, ao perfil dos trabalhadores do lazer, como status ocupacional em sua atuação no Programa Esporte e Lazer da Cidade. Para tanto, foram trazidos à análise os dados que se remetem a informações obtidas na esfera nacional e na esfera local, considerando, neste particular, o Distrito Federal e seu entorno.

De modo geral, pode-se apontar que os perfis dos trabalhadores do lazer são coincidentes nas esferas pesquisadas em relação às categorias "sexo", "estratos etários" e "tempo de permanência no programa". Considerando a noção com base na apropriação de Sorokin (1979), os resultados sugerem certa homogeneidade entre os trabalhadores do lazer nos níveis local e nacional.

$\mathrm{Na}$ esfera nacional algumas dispersões são evidenciadas, pois $2 \%$ dos trabalhadores do sexo masculino possuem menos de 18 anos de idade. Nessa esfera ainda registrou-se que $10 \%$ dos agentes do sexo feminino têm mais de 50 anos. No Distrito Federal e entorno outras dispersões demonstraram que $2,5 \%$ dos trabalhadores do sexo feminino possuem 14 anos de idade e outros cerca de $2,5 \%$ do sexo masculino já completaram 59 anos. Apesar dessas, a relação entre sexo e os estratos etários dos trabalhadores do lazer do Programa Esporte e Lazer da Cidade se expressa de forma similar nas esferas nacional e local, visto que há uma concentração, em termos etários, na faixa compreendida entre 20 e 40 anos.

Também é preciso observar que há uma relativa homogeneidade em relação às idades dos trabalhadores e trabalhadoras, expressando uma diferença pouco significativa de cinco anos. A faixa etária preponderante de homens que atuam no programa está compreendida entre 25 e 40 anos de idade, enquanto a das mulheres está entre 30 e 40 anos. Isso se dá tanto na esfera nacional como no Distrito Federal e entorno. Há, portanto, um indicador de que os homens entram mais precocemente no programa, enquanto as mulheres levam mais tempo até poderem nele ingressar. 
É interessante notar a extensa faixa etária em que se encontram os trabalhadores do lazer do PELC, que vai dos 14 aos 60 anos de idade. Isso se explica por uma particularidade do programa, que permite a participação de pessoas com menos de 18 anos, na qualidade de "agentes sociais". O objetivo do programa é o trabalho com o lazer comunitário, que, numa dimensão ampliada, pode abranger atividades físicas e esportivas que se reportem à competição, como por exemplo o futebol, mas também práticas corporais como o skate e hip hop. O que se leva em conta, prioritariamente, na contratação do agente social como bolsista do programa, é a sua habilidade com uma prática corporal de lazer, bem como o seu envolvimento com a comunidade (FIGUEIREDO; ALMEIDA, 2010, ALMEIDA et al., 2012).

Considerando as informações obtidas nacionalmente com respeito à escolarização, os dados revelam que $48 \%$ dos entrevistados possuem nível superior completo, enquanto que, dos $42 \%$ que possuem nível médio, mais da metade possui nível superior incompleto e, portanto, já teve, de alguma forma, mecanismos de acesso ao ensino superior. Para mais disso, há que se ressaltar que apenas $10 \%$ dos entrevistados possuem o ensino fundamental. Por fim, a inexistência de trabalhadores do lazer sem escolaridade na esfera nacional do programa, denota a satisfatória condição desses no que tange ao nível de escolarização.

Esses dados mostram haver certa divergência entre aqueles obtidos nas esferas nacional e local. A divergência está no fato de que, na esfera nacional a predominância dos trabalhadores possui nível superior completo, enquanto no nível local a predominância aponta para ensino médio completo. Este dado demonstra que a noção de invisibilidade das desigualdades sociais em relação ao Distrito Federal e entorno é reforçada. Tal constatação corrobora a ideia anteriormente apresentada de que a fotografia expressa pelo "Atlas da Exclusão Social no Brasil" pode não corresponder, em vários aspectos, à realidade estudada, ainda que sirva como parâmetro para se ter uma noção, em termos gerais, da situação geopolítica das diversas unidades federativas do Brasil (POCHMANN; AMORIM, 2003). 
De outra parte, tais informações têm importância para a implementação do programa pelo fato de que uma de suas principais ações é a política de formação para os trabalhadores do lazer, visando ao arregimentamento de ações/intervenções comunitárias nos âmbitos do esporte e do lazer. Assim, é necessária uma formação diretamente relacionada a aspectos culturais, artísticos ou esportivos (BRASIL, 2008, FIGUEIREDO; ALMEIDA, 2010). A formação dos agentes sociais representa um fator determinante da qualidade de sua ação pedagógica e política no PELC. Contudo, a formação específica não seria suficiente para compensar o desnível da escolarização dos agentes sociais do PELC, evidenciada no Distrito Federal em comparação ao universo nacional.

Cabe ainda, a respeito da análise desses dados, um registro. Diante da complexidade do cenário apresentado, a definição dos parâmetros da política de formação do programa exige a compreensão do diagnóstico e a construção de uma proposta que consiga abarcar pessoas com distintos níveis de escolaridade. Isso pressupõe não só uma formação específica diversa das existentes, mas também maneiras díspares de compreender a realidade social, pois diferentes formações subsidiam diferentes compreensões da realidade.

Sobre a relação entre a participação no processo de formação, o conhecimento dos objetivos, princípios e diretrizes e o tempo de permanência dos trabalhadores do lazer no programa, merecem destaque as seguintes considerações.

O desconhecimento dos objetivos, princípios e diretrizes pelo grupo 1 - menos de um mês no programa - parece-nos elementar, visto que reúne sujeitos que iniciaram o trabalho no programa recentemente e ainda não participaram dos processos formativos. Além disso, em termos percentuais, é baixa a quantidade de entrevistados, tanto na esfera nacional quanto na local, que indicaram desconhecimento. $\mathrm{O}$ mesmo se pode dizer daqueles entrevistados do grupo 5 - mais de dois anos no programa - que informaram não ter conhecimento dos aspectos destacados na pergunta. A quantidade é ínfima, se comparada com o total dos que disseram conhecer, levando-se em conta os dados coletados em ambas as esferas. 
Todavia, o que parece curioso é que os grupos 2, 3 e 4 - mais de um mês e menos de seis meses; mais de seis meses e menos de um ano; mais de um e menos de dois anos, respectivamente - são homogêneos em relação a esse quesito, fazendo-se supor que, ou não houve a adequada compreensão da pergunta por parte dos entrevistados do grupo 5 ou a apropriação dos objetivos, princípios e diretrizes do programa gera dúvidas naqueles que estão há mais tempo no programa. Esta última hipótese pode indicar uma falha no processo formativo ou no acompanhamento de quem efetivamente participa de tais processos, como se verifica pelo percentual de participantes que informou não ter participado de encontros pedagógicos, que foi respectivamente $16 \%$ em nível nacional e $6 \%$ em nível local. Conclui-se, assim, que a divergência em relação aos dados coletados, no que diz respeito ao conhecimento dos objetivos, princípios e diretrizes do programa, também pode estar associada à formação. Tal conclusão sugere a necessidade de avaliação e revisão das atividades desenvolvidas durante os encontros pedagógicos, como preconizam os estudos realizados por Coriolano et al. (2012), Stroschein e Zocche (2012) e Modesto et al. (2013), notadamente quando assinalam a necessidade de qualificação profissional como uma estratégia para a construção de outro olhar por parte dos agentes sociais - aqui entendidos como trabalhadores do lazer - em sua prática social na comunidade. Isto porque a formação continuada contribui para a redefinição de conceitos em princípio considerados inexoráveis, mas que, diante do processo formativo, podem ser reelaborados.

\section{CONSIDERAÇõES FINAIS}

Podemos inferir, diante dos dados apresentados e discutidos, que os trabalhadores do lazer, como status ocupacional, possuem perfil similar entre as esferas nacional e local, observadas algumas discrepâncias em relação ao nível de escolaridade, que na esfera nacional apresenta predominância de trabalhadores com nível superior completo, enquanto na esfera local a predominância aponta para ensino médio completo. 
Com referência ao tempo de permanência no programa e o conhecimento dos objetivos, princípios e diretrizes do mesmo, há uma clara associação entre o tempo de permanência no programa, a participação dos agentes nos encontros formativos e o conhecimento das noções fundamentais do programa. Assim, quanto mais tempo o trabalhador do lazer possuir no programa e de quanto mais encontros formativos participar, maior clareza terá dos objetivos, princípios e diretrizes do mesmo na construção de sua intervenção na comunidade.

Por fim, é importante destacar o fato anteriormente registrado de que há certa transitoriedade dos trabalhadores do lazer no programa, o que pode vir a limitar a constituição de quadros de lideranças locais, devendo ser este aspecto objeto de atenção de gestores públicos. Por um lado, essa transitoriedade pode representar descontinuidade, que limitaria a evolução do próprio programa em direção ao cumprimento de suas finalidades primárias. Por outro, a transitoriedade tende a gerar fragmentação e dificuldade para uma ação orientada em torno do estatuto da matricialidade. Esse situa a administração pública como uma plataforma de integração intensiva de programas e organizações. A matricialidade se configura como uma metodologia que viabiliza a construção compartilhada de projetos de intervenção entre diferentes interlocutores. Para além disso, tal perspectiva permitiria o crescimento pessoal e coletivo do trabalhador, ao mesmo tempo em que produz bens e serviços de caráter público (AMARAL; COSTA, 2012, p. 212). Trata-se de uma alternativa teórico-metodológica à gestão de políticas públicas, para alcance de resultados que visam superar a exclusão social a melhoria da qualidade de vida. 
Leisure's workers of the City's sport and leisure program: appointments about the profile definition

Abstract: The paper aims to characterize the profile of workers in leisure City's sport and leisure program. It based the analysis of the definition of leisure as workers occupational status. Data were collected through a questionnaire, at the national and in the Federal District. The results indicate the profile matching between the spheres studied. The discussion of the data indicated that there is an association between the length of stay in the program, the participation of agents in training meetings and knowledge of the fundamental concepts of the program. The continuing education is a key strategy for achieving the policy examined.

Keywords: Workers Leisure. Public Police. Leisure.

Trabajadores del ocio del Programa Deporte y Ocio de la Ciudad: una aproximación a la definición del perfil

Resumen: El trabajo tiene como objetivo caracterizar el perfil de los trabajadores del ocio del Programa Deporte y Ocio de la Ciudad. El fundamento del analysis es la definición de trabajadores del ocio como status ocupacional. Fuerón obtenidos datos, por medío de una encuesta, en los niveles nacional y districtal. Los resultados apuntan la coincidência de los perfiles entre los niveles pesquisados. El analysis indicó una associación entre el tiempo de trabajo en el programa, la participación de los agentes en formación y el conocimiento de las nociones fundamentales del programa. La formación representa una estrategia importante el programa.

Palabras-clave: Trabajadores del ocio. Política Pública. Ocio. 


\section{REFERÊNCIAS}

ALMEIDA, Bárbara Shausteck de; MARCHI JÚNIOR, Wanderley. O financiamento dos programas Federais de esporte e lazer no Brasil (2004 a 2008). Movimento, Porto alegre, v. 16, n. 4, p. 73-92, out./dez. 2010.

ALMEIDA, Dulce Filgueira de et al. Leisure in public policies in Brazil, participation, access and social inclusion. In: SPRACKLEN, Karl; ADAMS, Andrew (Org.). Sport, leisure and tourism politics and places. Eastbourne: LSA, 2012. p. 97-112.

AMARAL, Sílvia Cristina Franco; COSTA, Eduardo Tadeu. Possibilidades da matricialidade na administraçãoo pública do lazer. Movimento, Porto alegre, v. 18, n. 1, p. 205-220, jan./mar. 2012.

BRASIL. Ministério do Esporte. Material didático do Programa Esporte e Lazer da Cidade. Brasília: Ministério do Esporte, 2006.

BRASIL. Ministério do Esporte. Manual de orientação do Programa Esporte e Lazer da Cidade. Brasília: Ministério do Esporte, 2008.

BRASIL. Ministério do Esporte. Sistema de formação do PELC. Brasília. Disponível em http://www.esporte.gov.br/sndel/esporteLazer/estrategia1.jsp>. Acesso em: 19 maio 2011.

BOURDIEU, Pierre. Sociologia. São Paulo: Ática, 1983.

CORIOLANO, Maria Wanderleya de Lavor et al. Educação permanenente com agentes comunitários de saúde: uma proposta de cuidado com crianças asmáticas. Trabalho, Educação e Saúde, Rio de Janeiro, v. 10, n. 1, p. 37-59, mar./jun. 2012.

DURKHEIM, Émile. O suicídio: estudo sociológico. Lisboa: Presença, 1987.

FERES NETO, Alfredo; VIEIRA, Luiz Renato; ATHAYDE, Pedro. Estado, poder e programas sociais: o PELC e o Governo Lula. In: FILGUEIRA, Dulce; FERES NETO, Alfredo (Org.). Esporte e Lazer: a cidadania em construção. Brasília: Thesaurus, 2012. p. 21-56.

FIGUEIREDO, Pedro Osmar Flores de Noronha. Política e formação: o Programa Esporte e Lazer da Cidade no Distrito Federal e entorno. 2009. 136 f. Dissertação (Mestrado em Educação Física) - Faculdade de Educação Física, Universidade de Brasília, Brasília, 2009.

FIGUEIREDO, Pedro Osmar Flores de Noronha; ALMEIDA, Dulce Filgueira de. Educação e formação dos trabalhadores do Programa Esporte e Lazer da Cidade. In: ALMEIDA, Dulce Filgueira de et al. (Org.). Política, lazer e formação. Brasília: Thesaurus, 2010. p. 97-116.

GUTIÉRREZ, Francisco. Educação como práxis política. São Paulo: Summus, 1988. 
POCHMAN, Márcio; AMORIM, Ricardo. Atlas da exclusão social no Brasil. São Paulo: Cortez, 2003.

MODESTO, Maria do Socorro Andrade et al. Avaliação de curso técnico de agente comunitário de saúde sob a ótica dos egressos. Trabalho, Educação e Saúde, Rio de Janeiro, v. 10, n. 3, p. 387-406, nov. 2012/fev. 2013.

SOROKIN, Pitrim. O que é uma classe social? In: STAVENHAGEN, Rodolfo (Org.). Estrutura de classe e estratificação social. Rio de Janeiro: Zahar, 1979. p. 8493.

STAREPRAVO, Fernando Augusto; SOUZA, Juliano de; MARCHI JUNIOR, Wanderley. Políticas públicas de esporte e lazer no Brasil: uma proposta teórico-metodológica de análise. Movimento, Porto Alegre, v. 17, n. 3, p. 233-251, jul./set. 2011.

STROSCHEIN, Karina Amadori; ZOCCHE, Denise Antunes Azambuja. Educação permanente nos serviços de saúde: um estudo sobre as experiências realizadas no Brasil. Trabalho, Educação e Saúde, Rio de Janeiro, v. 9, n. 3, p. 505-519, nov. 2011/fev. 2012.

TELLES, Vera Lúcia. Direitos sociais: afinal do que se trata? Belo Horizonte: UFMG, 1999.

WEBER, Max. Economia e sociedade. Brasília: UnB, 1991.

Endereço para Correspondência:

Universidade de Brasília,

Faculdade de Educação Física, Campus Darcy Ribeiro, Gleba B,

CEP 70919-970,

Brasília, Distrito Federal, Brasil.

Telefone: (61) 3107-2500

Recebido em: 17.06.2013

Aprovado em: 20.11.2013

Movimento, Porto Alegre, v. 20, n. 01, p. 215-238, jan/mar de 2014. 